\title{
Medical Image of the Week: Paget-Schroetter Syndrome
}

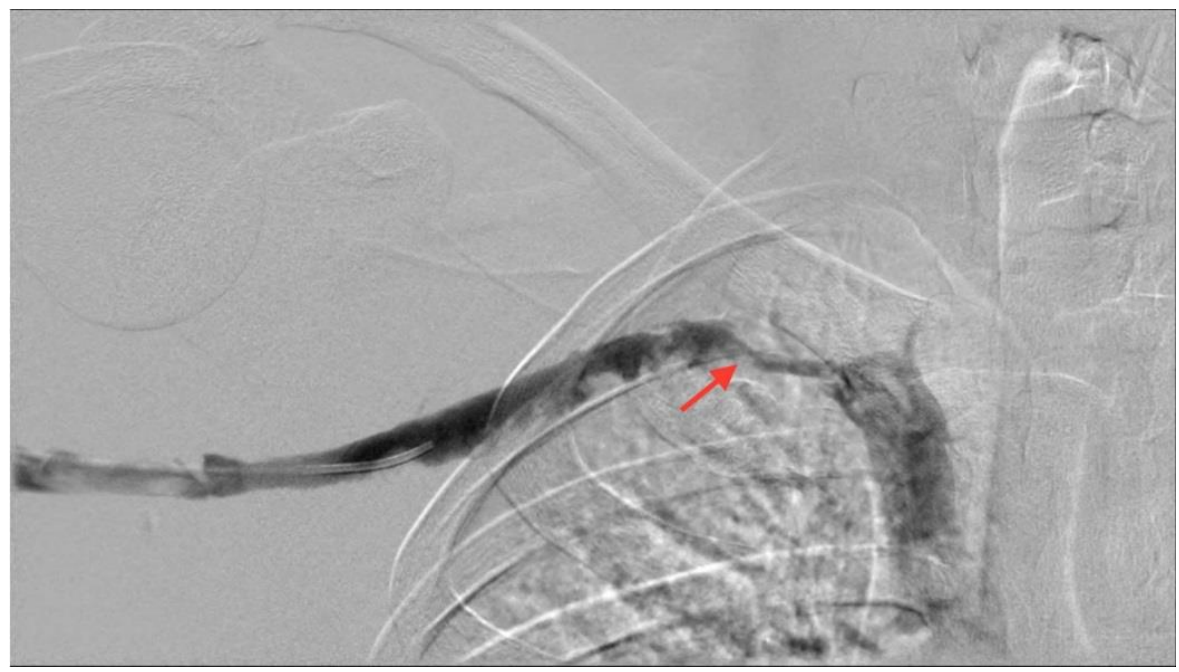

Figure 1. Venous contrast study demonstrating thrombosis and flow obstruction at the thoracic outlet (arrow).

A 22-year-old right-handed man developed acute swelling of his right upper extremity following a weekend of vigorous physical military training. There was no associated pain or numbness. Physical examination demonstrated edema of the right arm. Radial and ulnar pulses were intact, and neurological exam was normal. Venous doppler examination demonstrated thrombus in the subclavianaxillary venous system. A confirmatory venous contrast study was performed (Figure 1), followed by catheter directed lysis. Effort related thrombosis of the subclavian vein secondary to mechanical compression at the thoracic outlet is known as Paget-Schroetter Syndrome (1). Current treatment commonly includes catheter directed clot lysis and an arbitrary three-month period of systemic anticoagulation, followed by surgical resection of the first rib (2). Post-operative balloon angioplasty of the involved venous segment improves long-term results (3). This patient underwent successful lysis, was discharged on oral rivaroxaban, and has been referred to thoracic surgery for consideration of rib resection.

Charles Van Hook MD and Ken Hirasaki MD

Longmont United Hospital

Longmont, Colorado USA

\section{References}

1. Kucher N. Deep-vein thrombosis of the upper extremities. N Engl J Med. 2011;364:861-9.[CrossRef] [PubMed]

2. Engelberger RP, Kucher N. Management of deep vein thrombosis of the upper extremity. Circulation. 2012;126:768-73. [CrossRef] [PubMed]

3. Illif KA, Doyle AJ. A comprehensive review of Paget-Schroetter syndrome. J Vasc Surg. 2010;51:1538-47. [CrossRef] [PubMed] 